\title{
Inspiring, Exploring, Activating and Organizing: A Framework for Improving Communication Skills and Product Knowledge in Call Center
}

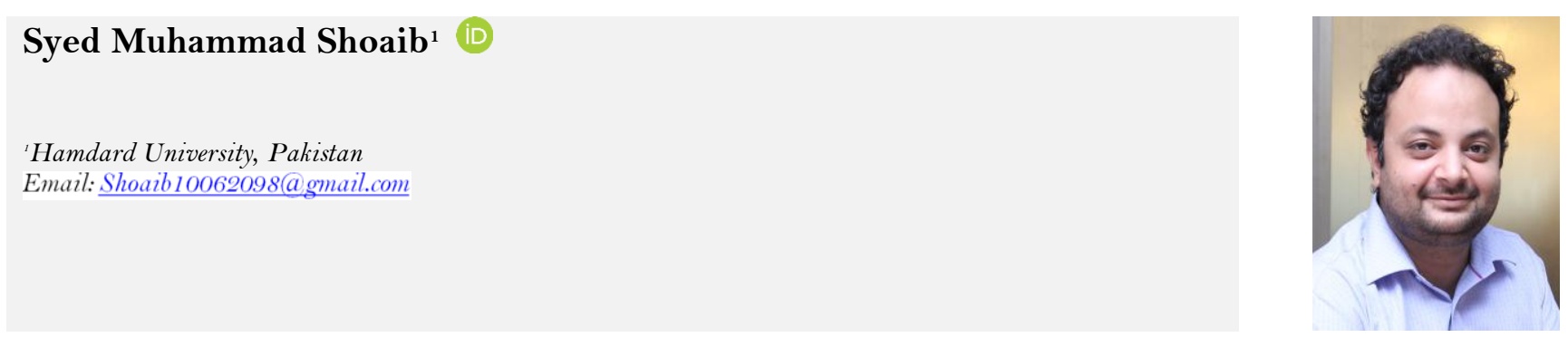

\begin{abstract}
The rapid growth of call centers and customer dependency on call center puts very high demands and standards for the call center management in terms of customer satisfaction. Beside operational management areas like forecasting, scheduling, recruitment and hiring, training plays a significant role in achieving customer satisfaction from call centers. This paper deals with the training in a call center and suggest a framework for training to improve customer satisfaction by improving product knowledge and communication skills of call center agents. The traditional training programs in call centers heavily focuses on forced learning methods and traditional lecture base approach. This work provides a framework and establishes four principles to reform training program in order to improve communication skills and product knowledge of call center agents. The first principle "Inspiring" focuses on personal and professional development of call center agent through call center. The second principle "Exploring" focuses on self-learning through designed explorations ,the third principle "Activating" focuses on activity base learning for communications skills and product knowledge in call centers and the last principle "Organizing" aims at incorporation of these principals into training programs and in training curriculum for effective training execution according to the guidelines provided in the framework.
\end{abstract}

Keywords: Product knowledge, Communication skills, Call centers, Training, Framework.

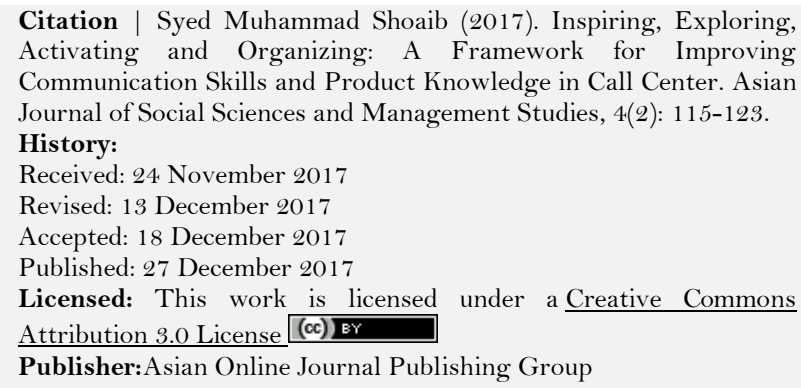

Citation | Syed Muhammad Shoaib (2017). Inspiring, Exploring, Activating and Organizing: A Framework for Improving Communication Skills and Product Knowledge in Call Center. Asian Journal of Social Sciences and Management Studies, 4(2): 115-123. History:

Received: 24 November 2017

Revised: 13 December 2017

Accepted: 18 December 2017

Published: 27 December 2017

Licensed: This work is licensed under a Creative Commons

Attribution 3.0 License (cc) $\mathbf{E}$

Publisher: Asian Online Journal Publishing Group

\section{Contents}

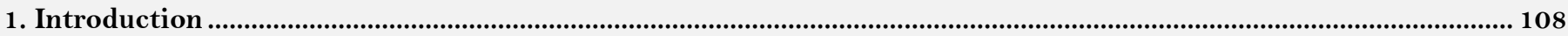

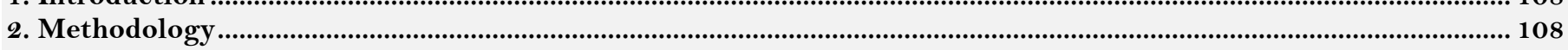

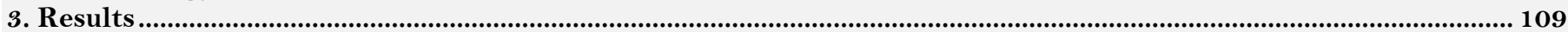

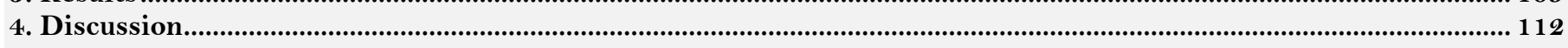

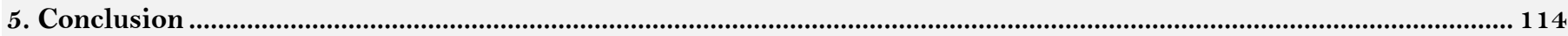

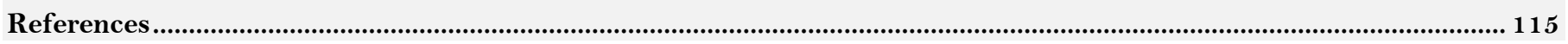




\section{Introduction}

Customer service is integral to the success of every business unit, whether it is a small scale business or a large enterprise, ever increasing customer expectations and increasing tendency of sharing bad experience on social media there is a tremendous pressure on companies to maintain high level of customer service. The decrease in cost of telecommunication and information technology equipment made a significant role in the emergence of call centers and now almost every industry and organization is interested or already deployed call center as their prime customer facing channel. Call centers now termed as the "Public Face" for many businesses, have a constantly increasing significance in customer attainment and retention. The rapid growth of call centers and customer dependency on call centers puts very high demands and standards for the call center management in terms of customer satisfaction thus the importance of call center and its operational effectiveness and efficiency is imperial in providing quality services to its customers. Call Center performance is mainly a composition of a) how quickly customer call is being answered b) how the call is being handled. The Organization measures its call center representatives on two major compositions, Adherence Measures and Quality of a Call. The first measurement i-e “The Adherence Measures” include adherence to Login time ,Average Handling time ,Hold time ,talk time etc. The adherence measure is not related to this research directly. This research deals with the second segment of agent performance measurement i-e "The Quality of a Call" i-e how well agent performs in the call with respect to "Communication Skills" and delivery of qualified information to customers labelled as "Product Knowledge".

Call center faces variety of challenges due to which call centers need to strive very hard to achieve optimal customer satisfaction. Majority of customers approach call center for issues in service, acquiring services and for general information. Thus the importance of call center and its operational effectiveness and efficiency is imperial in providing quality services to its customers. Call Center agent when equipped with all the necessary knowledge and accurate information can be able to deliver relevant knowledge through excellent communication skills which can significantly improve customer experience over call.

Many businesses rely on call centers for their marketing needs and to serve their customers. Call centers employee's training period last typically for few weeks and call center agents are very tightly monitored as they respond to hundreds of customer queries on daily basis (Tjosvold et al., 2014). In call centers training is typically aimed for (1) New Staff and (2) Existing Staff. New hires typically got training for few weeks before they put into floor shop, while training for existing staff can be both scheduled and unscheduled. No matter what segment of staff, training play a very key role in ascertaining employee and organizational performance which in turns results in customer satisfaction.

There are several learning theories for training which explain how people learn and each theory refer to distinct aspect of how people learn for example; a) Social Learning theory identifies four aspects of learning which are Attention, Retention, Motor reproduction and motivational (Noe, 2010) Reinforcement Theory developed by B.F. Skinner, according to which behavior is a result of its consequences, c) Goal Theory deal with organizational psychology and describe the relationship between performance and goal setting. It is also very beneficial in designing training programs, assigning trainees with specific and challenging goals can result in more commitment and involvement and it also create satisfaction among trainees as they attain their goals, d) Adult Learning Theory which is described as the art and science of adult learning, in applied terms, it means that teaching for adults requires focusing more on the procedure and less on the content being educated and approaches such as case studies, character playing, simulations, and self-evaluation are of maximum benefit rather the lecture, e) Information Processing Theory (IPM) not only focuses on internal mechanism of learning that enable us to store, capture, retrieve and respond to messages but also highlights the impact of outside factors on learning.

There are number of training frameworks or models that have yield significant performance improvement in organizations. These well-known training models are Instructional Systems Design (ISD), The five step Design, Analysis, Evaluation, Implementation, and Development model framework of the ADDIE covers all the steps of ISD model (Dick et al., 2011; Gustafson and Branch, 2011). In ADDIE model design stage focuses on how the learner learn, in the development stage teaching content are formulated, next stage involves applying the training, building the teaching atmosphere, and placing teaching supplies in the teaching environment, in the final stage performance and outcomes are evaluated (Hsu et al., 2014). Human performance technology (HPT) comprises of ideologies from arenas such as social psychology, instructional systems design, organizational development and human resources management (Klein and Fox, 2004). HPT helps organizations to identify performance gaps, offers interventions for performance enhancement, implementation of change management process and results evaluation.

The purpose of the training programs is to increase the individual job performance (Bain et al., 2002; Holman et al., 2007) employee performance and organizational performance. This study focuses on developing a new framework to improve the "Communication Skills "and "Product Knowledge" of Call Centre agents. The research targets improvement in communication skills and product knowledge through the implementation of suggested framework presented in this study. The framework is designed by focusing on how to improve the engagement of trainees in training programs, how to develop motivation for self-directed learning for personal and professional development and how to reduce attrition rate. The significance of training in achieving customer satisfaction is of great value and this work help in achieving customer satisfaction and improve agent performance through new training framework presented in this research.

\section{Methodology \\ 2.1. Research Tool}

Quantitative and observational research was carried out to test the framework. Previous researches exist in abundance regarding training frameworks however this research suggest an entirely new perspective for trainings in service industries specifically in call centers. An observational research technique is used to test the framework. The research conducted was quantitative in nature and took the form of observational research. The designed framework was implemented to sample and the findings were than compared to set of another sample on which the framework was not applied. 


\subsection{Sampling}

Two types of samples, A and B, were collected (Table 1). For sample "A" 5 agents were randomly selected and 5 calls of each randomly selected agents were evaluated and observation were recorded on the observation forms (Table 2). For sample "B" 5 agents were randomly selected and 5 calls of each randomly selected agents were evaluated and observation were recorded on the observation forms (Table 3). Marks deduction criteria for communication skills (Table 4a) and product knowledge (Table 4b) against which calls are evaluated were also formulated. Both these units are being measured through certain parameters. In this research certain parameters of "communication skills" and "product knowledge" has been taken and reflected in "Observation Forms". These observations forms then served as the basis for data collection and data analysis.

\subsection{Data Collection}

The call recordings of both the samples i-e "Sample A" and "Sample B" were analyzed against the observation forms of communication skills and product knowledge. Sample "A" was observed in the light of observation form of communication skills and sample "B" was evaluated against in the light of observation of product knowledge. The analysis was conducted through data that is naturally occurring in the forms of call recordings. The customer service department in the company where the research is conducted is consist of more than 350 new-hired agents. Compared data is the cumulative average of first month score of five newly-hired agents on which no implementation of this framework was applied against the parameters identified in the observation forms. Data obtained was then compared with data available of Sample "A" and "B".

Table-1. Sample Details

\begin{tabular}{l|l|l|l}
\hline Sample Name & Category & Sample Size & Framework Implementation Details \\
\hline "A" & Newly-Hired Agents & 5 & $\begin{array}{l}\text { Partial Implementation of Exploring and } \\
\text { Activating principle for some learning units } \\
\text { related to Communication Skills }\end{array}$ \\
\hline "B" & Newly-Hired Agents & 5 & $\begin{array}{l}\text { Partial Implementation of Exploring and } \\
\text { Activating principle for some learning units } \\
\text { related to Product Knowledge }\end{array}$ \\
\hline
\end{tabular}

Table-2. Observation Form Sample "A"

\begin{tabular}{l|l|l|l|l|l|l}
\hline & Agent \\
Name & $\begin{array}{l}\text { Number of } \\
\text { Calls } \\
\text { Observed }\end{array}$ & $\begin{array}{l}\text { Casual Greeting } \\
\text { or Greeting not } \\
\text { clear } \\
\text { (Total Marks 25) }\end{array}$ & $\begin{array}{l}\text { Pace of } \\
\text { Greeting Not } \\
\text { Accurate } \\
\text { (Total Marks } \\
\mathbf{5 0}\end{array}$ & $\begin{array}{l}\text { Not Using } \\
\text { Professional } \\
\text { words } \\
\text { (Total Marks } \\
\mathbf{1 5 0}\end{array}$ & $\begin{array}{l}\text { Non } \\
\text { Energetic } \\
\text { (Total Marks } \\
\mathbf{1 5 0})\end{array}$ & $\begin{array}{l}\text { Lack of } \\
\text { Courtesy } \\
\text { (Total Marks } \\
\mathbf{1 5 0})\end{array}$ \\
\hline Agent 1 & 5 & 25 & 40 & 90 & 90 & 120 \\
\hline Agent 2 & 5 & 20 & 30 & 90 & 120 & 120 \\
\hline Agent 3 & 5 & 25 & 50 & 60 & 60 & 90 \\
\hline Agent 4 & 5 & 20 & 40 & 120 & 90 & 120 \\
\hline Agent 5 & 5 & 25 & 120 & & 120 & 120 \\
\hline
\end{tabular}

Table-3. Observation Form Sample "B"

\begin{tabular}{|c|c|c|c|c|c|c|}
\hline $\begin{array}{l}\text { Agent } \\
\text { Name }\end{array}$ & $\begin{array}{l}\text { Number of } \\
\text { Calls } \\
\text { Observed }\end{array}$ & $\begin{array}{l}\text { Un Qualified } \\
\text { Information Given } \\
\text { (Total Marks 200) }\end{array}$ & $\begin{array}{l}\text { CCR Did not try to } \\
\text { Upsell/Cross Sell } \\
\text { (Total Marks 200) }\end{array}$ & $\begin{array}{l}\text { CCR Did not } \\
\text { pitch } \\
\text { offer } \quad \text { the } \\
\text { Marks 200) }\end{array}$ & $\begin{array}{l}\begin{array}{l}\text { Did not } \\
\text { Drive the } \\
\text { call }\end{array} \\
\text { (Total } \\
\text { Marks 200) } \\
\end{array}$ & $\begin{array}{l}\text { Poor System } \\
\text { Handling } \\
\text { (Total } \\
\text { Marks 200) }\end{array}$ \\
\hline Agent 1 & 5 & 160 & 120 & 160 & 120 & 120 \\
\hline Agent 2 & 5 & 120 & 80 & 80 & 120 & 120 \\
\hline Agent 3 & 5 & 80 & 120 & 120 & 80 & 80 \\
\hline Agent 4 & 5 & 120 & 120 & 120 & 120 & 120 \\
\hline Agent 5 & 5 & 160 & 120 & 120 & 120 & 120 \\
\hline
\end{tabular}

Table-4(a). Marks deduction criteria for "Communication Skills"

\begin{tabular}{l|l|l}
\hline KQI(s) & Deficiencies & Deduction \\
\hline \multirow{4}{*}{ Communication Skills } & Casual Greeting or Not Clear & 5 \\
\cline { 2 - 3 } & Pace of greeting is not accurate & 10 \\
\cline { 2 - 3 } & Didn't use professional words & 30 \\
\cline { 2 - 3 } & Lazy/Non Energetic & 30 \\
\cline { 2 - 3 } & Courtesy & 30 \\
\hline
\end{tabular}

Table-4(b). Marks deduction criteria for "Product Knowledge"

\begin{tabular}{l|l|l}
\hline KQI(s) & DEFICIENCIES & DEDUCTION \\
\hline Product Knowledge & Poor System Handling & 40 \\
\hline & Did not Drive the call & 40 \\
\hline & CCR Did not try to Upsell/Cross Sell & 40 \\
\hline & CCR Did not pitch the offer & 40 \\
\hline & Unqualified information given & 40 \\
\hline
\end{tabular}

\section{Results}

The framework is only partly applied to newly hired agents. In order to observe impact on product knowledge and communication skills observation forms for each is developed and data is collected and then analyzed according 
to the parameters set in these observations forms. Data is collected on excel and observations were made after listening the call recordings of samples and comparison was drawn between agents who does not go through the training according to proposed framework and between those on which this framework is implemented partly. These samples are selected through purposive sampling method and uses observation forms to analyze the results. This framework was partly implemented to two separate batches of newly hired call center agents.

\subsection{Data Analysis and Comparison}

\section{Sample "A"}

Following segments of framework is applied to sample "A"

1. Some Exploration Activities for communication Skills

2. Activations for creating motivation for better communication Skills

3. Brief Activity of setting communication goals

Data was collected against two different samples and was compared and analyzed with the data of agents on which the framework was not applied (Figure 1). Data is analyzed and mean is taken as a source of comparison. Compared data is the cumulative average of first month score of five newly-hired agents on which no implementation of this framework was applied against the parameters identified in the observation forms (Table 5). Data obtained was then compared with data available of Sample "A" (Figure 2). It was evident from data comparison that there is no subtle difference between the two compared data, this suggest that in order to validate the impact of this framework it is strongly recommended that the framework is to be applied on full scale .

Table-5. Average of Sample "A"

\begin{tabular}{|c|c|c|c|c|c|c|}
\hline \multirow[t]{2}{*}{$\begin{array}{l}\text { Agent } \\
\text { Name }\end{array}$} & \multirow[t]{2}{*}{$\begin{array}{l}\text { Number of Calls } \\
\text { Observed }\end{array}$} & $\begin{array}{l}\text { Casual Greeting } \\
\text { or Greeting not } \\
\text { clear }\end{array}$ & $\begin{array}{l}\text { Pace of } \\
\text { Greeting } \\
\text { Not } \\
\text { Accurate } \\
\end{array}$ & $\begin{array}{l}\text { Not Using } \\
\text { Professional } \\
\text { words }\end{array}$ & Non Energetic & $\begin{array}{ll}\text { Lack of } \\
\text { Courtesy }\end{array}$ \\
\hline & & (Total Marks 25) & $\begin{array}{l}\text { (Total } \\
\text { Marks 50) } \\
\end{array}$ & $\begin{array}{l}\text { (Total Marks } \\
150)\end{array}$ & $\begin{array}{ll}\text { Total Marks } \\
150)\end{array}$ & $\begin{array}{l}\text { Total } \\
\text { Marks 150) } \\
\end{array}$ \\
\hline Agent 1 & 5 & 25 & 40 & 90 & 90 & 120 \\
\hline Agent 2 & 5 & 20 & 30 & 90 & 120 & 120 \\
\hline Agent 3 & 5 & 25 & 50 & 60 & 60 & 90 \\
\hline Agent 4 & 5 & 20 & 40 & 120 & 90 & 120 \\
\hline Agent 5 & 5 & 25 & 40 & 120 & 120 & 120 \\
\hline Average & & 23 & 37 & 96 & 96 & 114 \\
\hline
\end{tabular}

Table-6. Average of Compared Data

\begin{tabular}{l|l|l|l|l|l|l}
\hline \multirow{2}{*}{$\begin{array}{l}\text { Agent } \\
\text { Name }\end{array}$} & $\begin{array}{l}\text { Number } \\
\text { of Calls } \\
\text { Observed }\end{array}$ & $\begin{array}{l}\text { Casual Greeting } \\
\text { or Greeting not } \\
\text { clear }\end{array}$ & $\begin{array}{l}\text { Pace } \\
\text { Greeting Not } \\
\text { Accurate }\end{array}$ & $\begin{array}{l}\text { Not Using } \\
\text { Professional } \\
\text { words }\end{array}$ & $\begin{array}{l}\text { Non } \\
\text { Energetic }\end{array}$ & Lack of Courtesy \\
\cline { 3 - 7 } & & $\begin{array}{l}\text { (Total Marks 25) } \\
\mathbf{5 0}\end{array}$ & 30 & $\begin{array}{l}\text { (Total } \\
\text { Marks 150) }\end{array}$ & $\begin{array}{l}\text { (Total } \\
\text { Marks 150) }\end{array}$ & (Total Marks 150) \\
\hline Agent 1 & 5 & 15 & 40 & 60 & 120 & 90 \\
\hline Agent 2 & 5 & 25 & 40 & 120 & 90 & 120 \\
\hline Agent 3 & 5 & 25 & 30 & 90 & 60 & 90 \\
\hline Agent 4 & 5 & 25 & 40 & 120 & 60 & 120 \\
\hline Agent 5 & 5 & 20 & $\mathbf{3 5}$ & 120 & 120 & 120 \\
\hline Average & & $\mathbf{2 2}$ & & $\mathbf{1 0 2}$ & $\mathbf{9 0}$ & $\mathbf{1 0 8}$ \\
\hline
\end{tabular}

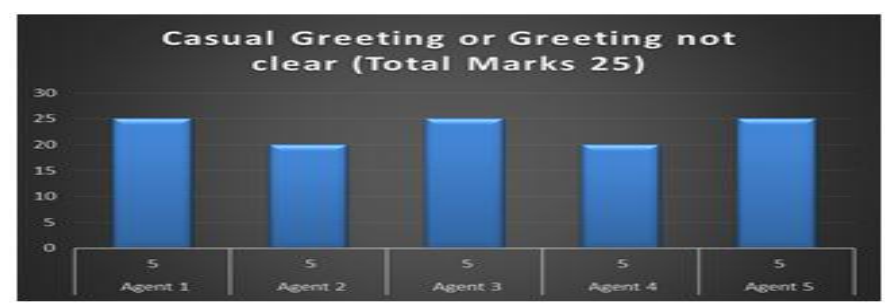

(a)

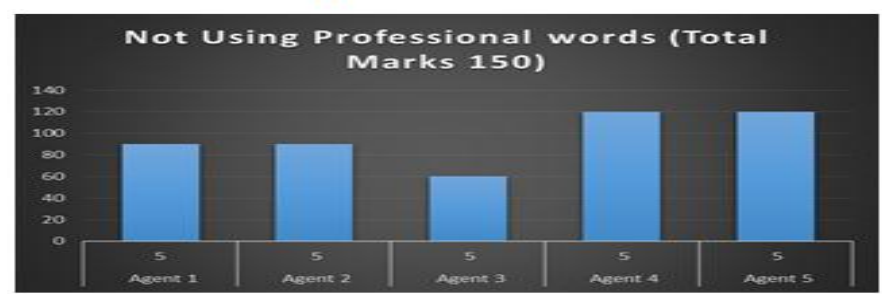

(c)

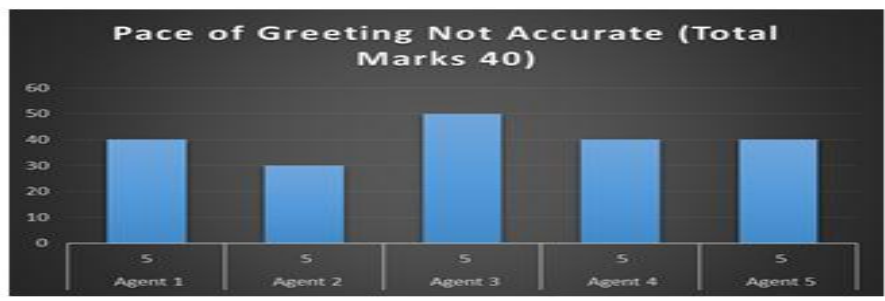

(b)

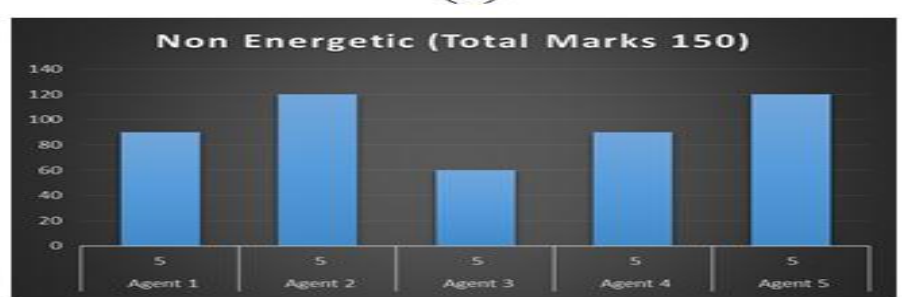

(d)

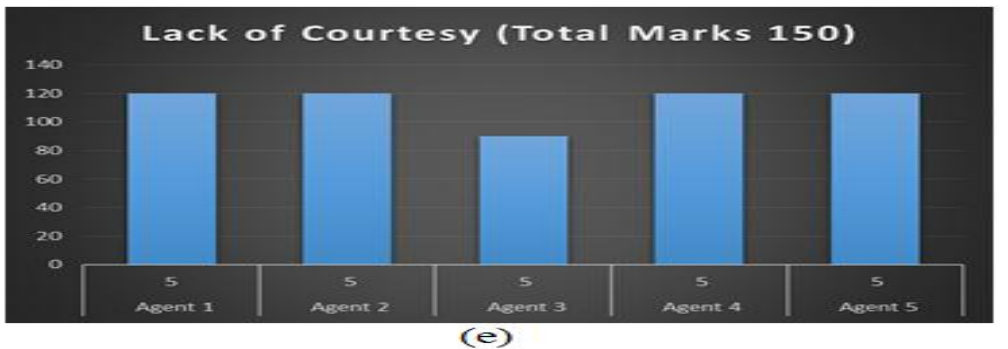

Figure-1. Bar Graph a) casual greeting b) Pace of greeting not accurate c) Not Using Professional words d) non energetic greeting e) lack of courtesy 


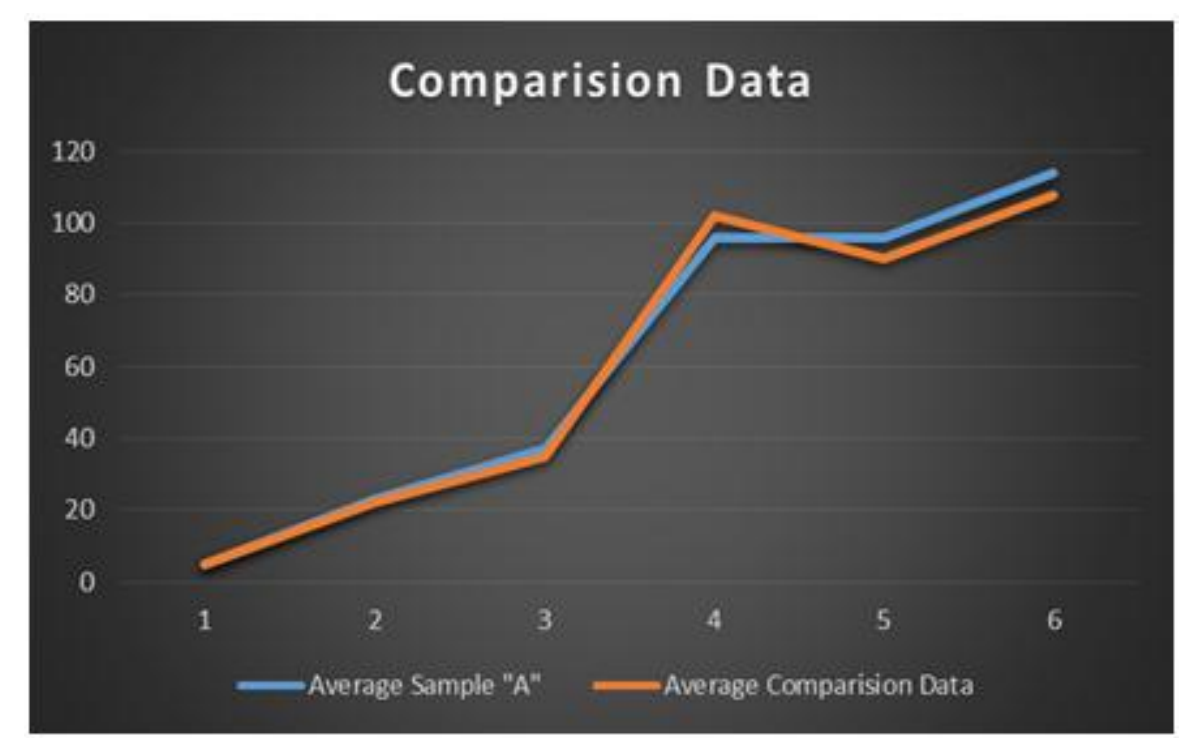

Figure-2. Data Comparison Sample “A”

Sample “B”

Following segments of framework is applied to sample "B",

1. Some Exploration Activities for product knowledge of Learning units "X" and "Y"

2. Some Activations for product knowledge of Learning units " $\mathrm{X}$ " and "Y"

Data is analyzed and mean is taken as a source of comparison. Compared data (Table 7) is the cumulative average of first month score of five newly-hired agents on which no implementation of this framework was applied against the parameters identified in the observation forms (Figure 3). Data obtained was then compared with data available of Sample "B" (Figure 4). It is obvious from data comparison that there is no subtle difference between the two compared data ,this suggest that in order to validate the impact of this framework it is strongly recommended that the framework is to be applied on full scale .

Table-7. Average of Sample "B"

\begin{tabular}{|c|c|c|c|c|c|c|}
\hline \multirow{2}{*}{$\begin{array}{l}\text { Agent } \\
\text { Name }\end{array}$} & \multirow{2}{*}{$\begin{array}{l}\text { Number of } \\
\text { Calls } \\
\text { Observed }\end{array}$} & $\begin{array}{l}\text { Un Qualified } \\
\text { Information } \\
\text { Given }\end{array}$ & $\begin{array}{l}\text { CCR Did not try } \\
\text { to Upsell/Cross } \\
\text { Sell }\end{array}$ & \multirow{2}{*}{$\begin{array}{l}\text { CCR Did not } \\
\text { pitch the } \\
\text { offer (Total } \\
\text { Marks 200) }\end{array}$} & $\begin{array}{l}\text { Did not Drive } \\
\text { the call }\end{array}$ & $\begin{array}{l}\text { Poor System } \\
\text { Handling }\end{array}$ \\
\hline & & $\begin{array}{l}\text { (Total Marks } \\
\text { 200) }\end{array}$ & $\begin{array}{ll}\text { (Total } & \text { Marks } \\
200) & \\
\end{array}$ & & $\begin{array}{l}\text { (Total Marks } \\
\text { 200) }\end{array}$ & $\begin{array}{l}\text { (Total Marks } \\
\text { 200) }\end{array}$ \\
\hline Agent 1 & 5 & 160 & 120 & 160 & 120 & 120 \\
\hline Agent 2 & 5 & 120 & 80 & 80 & 120 & 120 \\
\hline Agent 5 & 5 & 160 & 120 & 120 & 120 & 120 \\
\hline Average & 5 & 128 & 112 & 120 & 112 & 112 \\
\hline
\end{tabular}

Table-8. Average of Compared Data

\begin{tabular}{|c|c|c|c|c|c|c|}
\hline \multirow{2}{*}{$\begin{array}{l}\text { Agent } \\
\text { Name }\end{array}$} & \multirow{2}{*}{$\begin{array}{l}\text { Number of } \\
\text { Calls } \\
\text { Observed }\end{array}$} & $\begin{array}{l}\text { Un Qualified } \\
\text { Information } \\
\text { Given }\end{array}$ & $\begin{array}{l}\text { CCR Did not try } \\
\text { to Upsell/Cross } \\
\text { Sell }\end{array}$ & \multirow{2}{*}{$\begin{array}{l}\text { CCR Did not } \\
\text { pitch the } \\
\text { offer (Total } \\
\text { Marks 200) }\end{array}$} & $\begin{array}{l}\text { Did not Drive } \\
\text { the call }\end{array}$ & $\begin{array}{l}\text { Poor System } \\
\text { Handling }\end{array}$ \\
\hline & & $\begin{array}{l}\text { (Total Marks } \\
\text { 200) }\end{array}$ & $\begin{array}{ll}\text { Total } & \text { Marks } \\
200) & \\
\end{array}$ & & $\begin{array}{l}\text { (Total Marks } \\
\text { 200) }\end{array}$ & $\begin{array}{ll}\text { Total } & \text { Marks } \\
200) & \\
\end{array}$ \\
\hline Agent 1 & 5 & 160 & 40 & 120 & 160 & 80 \\
\hline Agent 2 & 5 & 120 & 120 & 80 & 120 & 80 \\
\hline Agent 3 & 5 & 60 & 80 & 80 & 40 & 120 \\
\hline Agent 4 & 5 & 120 & 160 & 120 & 120 & 160 \\
\hline Agent 5 & 5 & 120 & 120 & 120 & 120 & 120 \\
\hline Average & 5 & 116 & 104 & 104 & 112 & 112 \\
\hline
\end{tabular}




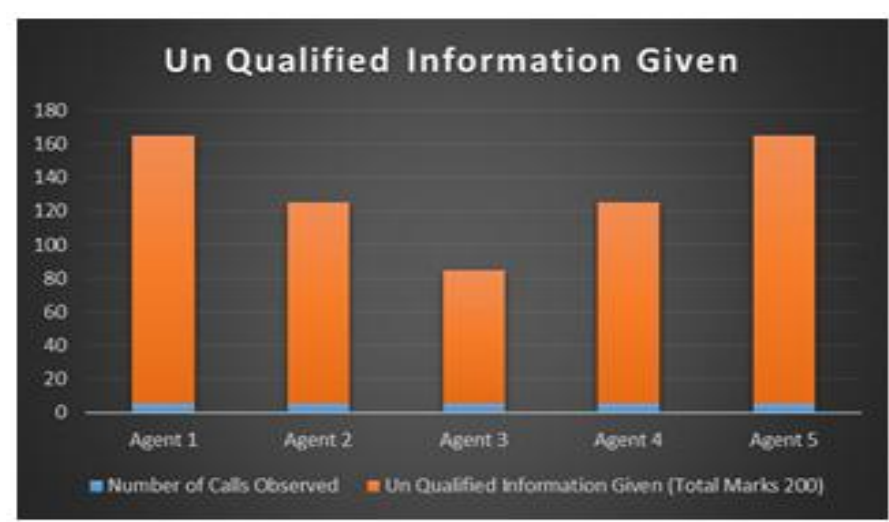

(a)

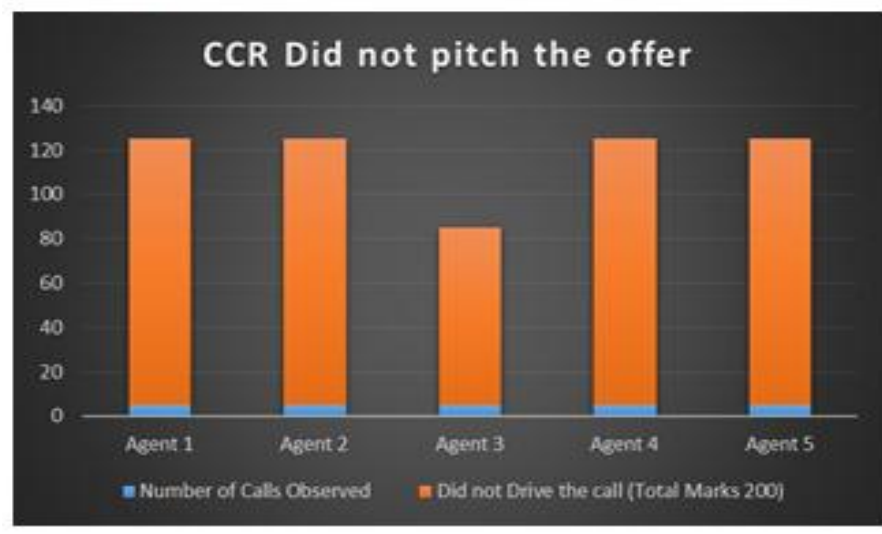

(c)

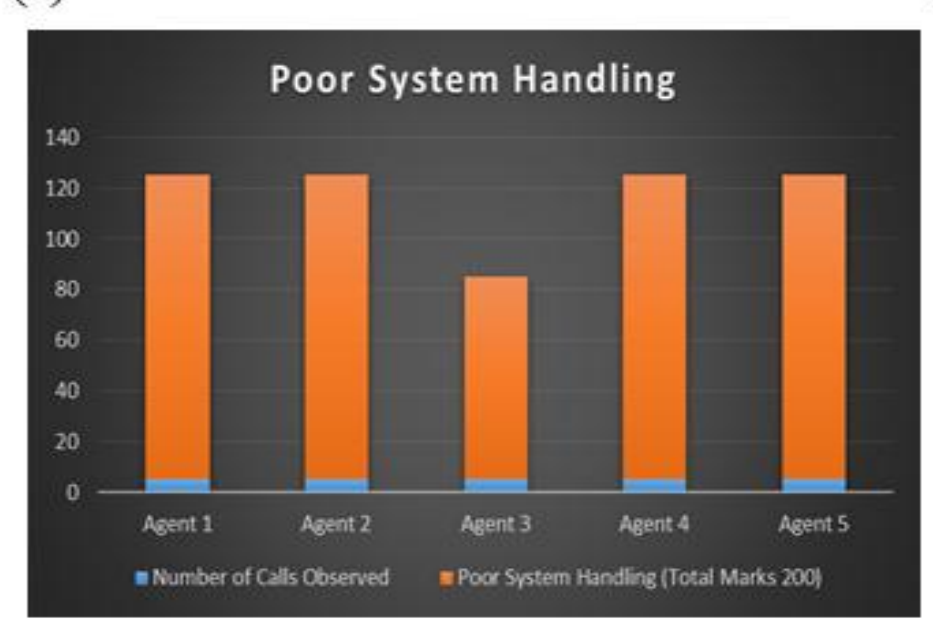

(e)

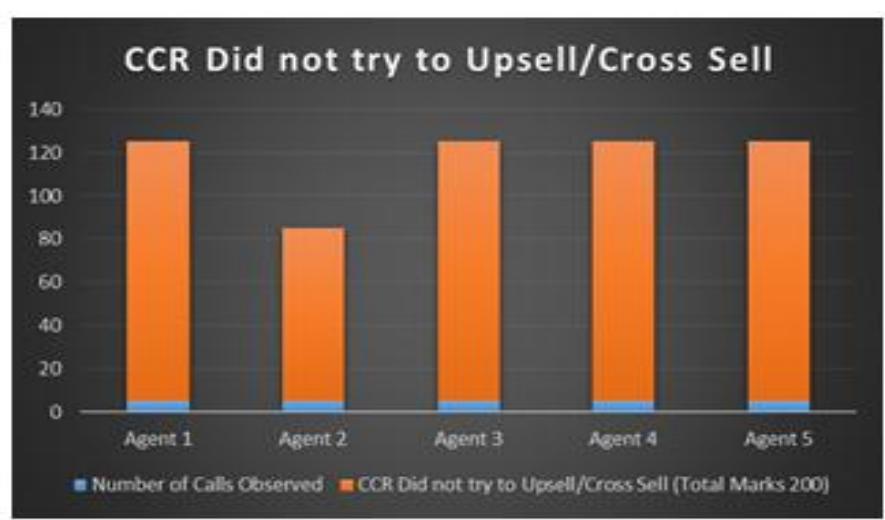

(b)

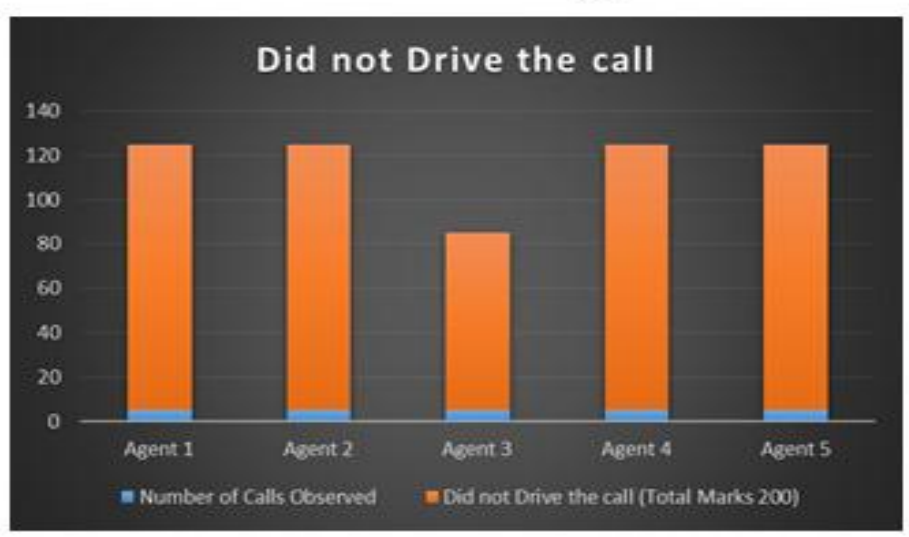

(d) the call (e) poor system handling

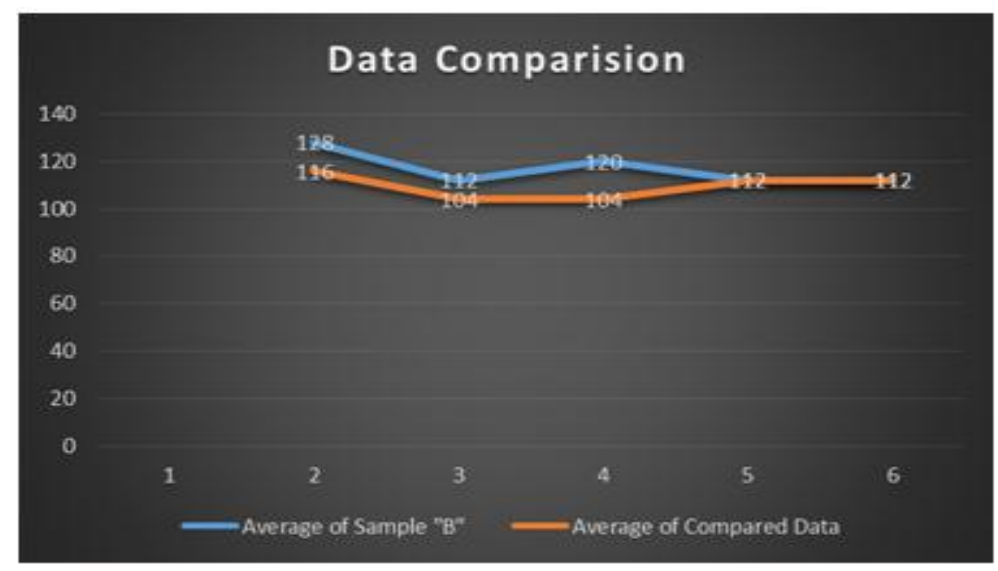

Figure-4. Data Comparison Sample “A”

\section{Discussion}

The purpose of this research is to improve the product knowledge and communication skills of call center agents by designing a new training framework. This framework establishes 4 key principals to increase the effectiveness of training program in call centers for the improvement in communication skills and product knowledge of a call center agent. This framework is specially designed to conduct training of new inductees however the principles and guidelines mentioned in this framework can be very helpful for all call center agents either new or old. This framework can also help in building effective training content related to communication skills and product knowledge 


\section{a) Inspiring}

According to this principle trainer first need to build the motivation in trainees by building motivation for call center. Inspiring principle create deep inspiration in trainees by transforming their mindset about call center. The call center job is often viewed as a monotonous job with limited window of growth, however the impact call center can create in attitude, emotional management and in learning ability is mostly overlooked. This framework identifies these "impacts" which not only help call center agents in progression of their professional career but can also help in transforming personal life. The theme of this inspiration principal is "Person First and Organization Second". This theme at first glance may seem rude to the organizations but in depth analysis will open many avenues. Many organizations focus on the organizational gains first, according to this principal to create the lasting inspiration the inspirations shall first focus on the individual as the growth in individual will directly affect the organization performance, with this little shift of mindset that is "Person First and Organization Second" call centers would not only able to achieve greater productivity but can also help in reducing turnover. The two suggested "Inspirations" which can transform call center agents from this "Inspiring" principle are (a) Impact of Call Center and (b) Presenting Success Stories. For the designed inspiration of "Impact of Call Center" trainer shall demonstrate the transformation call center can bring in trainee which can benefit trainee in his/her professional and personal life. The Job in a call center is tough but with this job there are many revolutions which call center agent can bring in his life during stay in call Centre. The job of a trainer is to effectively design and communicate these transformations and also connect these transformations to carrier progression. Some of these transformation that trainer need to cover in "Impact of Call Center" are (1) Gaining Self-Discipline (2) Change in Attitude through Stress Management (3) Learning Anger Management (4) Refining Communication Skills. All these transformation can greatly impact the personal and professional development of call center agent and help in changing the vision about call centers. The second "Inspiration" can be achieved through presenting success stories of current and former call center staff. Presenting success stories at the beginning of a training of new inductees can greatly inspire trainees.

\section{b) Exploring}

After the execution of "Inspiring" principle the next phase is to develop content by using guidelines mentioned in "Exploring" principle. The theme behind exploring is to enable self-learning. According to this principle trainees first need to explore learning areas by their own before trainer provides any assistance regarding the learning unit. All these exploration need to be structured and predesign. The "Exploring" principle identifies several such exploring activities for communication skills and product knowledge. "Explorations" suggested for call center industry for the improvement in communication skills are (1) Exploring communication skills by Calling Helpline (2) Exploring communication skills by visiting Floor and observing Live Calls (3) Exploring by watching videos of best communicators, by using the theme developed in "Exploring" principle trainer can also create many other explorations. The theme of this principle is that trainees need to first self-explore about communication skills and products. After these explorations trainer may proceed for formal deliverance of knowledge according to curriculum design and sequence. For product knowledge explorations are (1) Calling helpline (2) Exploring by accessing official information portal (3) Exploring by watching product commercials. Trainer can also developed other exciting explorations to enable trainees to explore products.

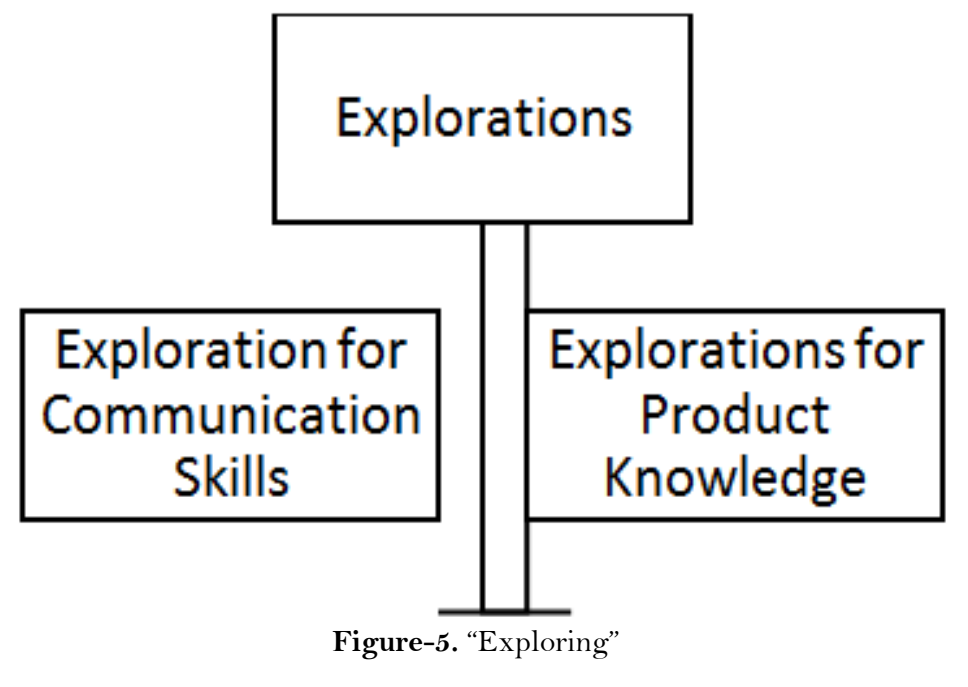

\section{c) Activating}

The "Activating" principle comprehensively focuses on designing of engaging and interesting activations which can be executed before, during and after formal lectures. According to this principle, activations are designed to increase learner engagement and effectiveness of the learning. Through Activations trainee would get more involved in the training. Activations for communication skills revolves around three philosophies i-e in order for agent to have a better communication skills agent should be (1) Motivated to learn communication skills (2) Have to set communication goals and (3) Shall developed cognitive skills. 


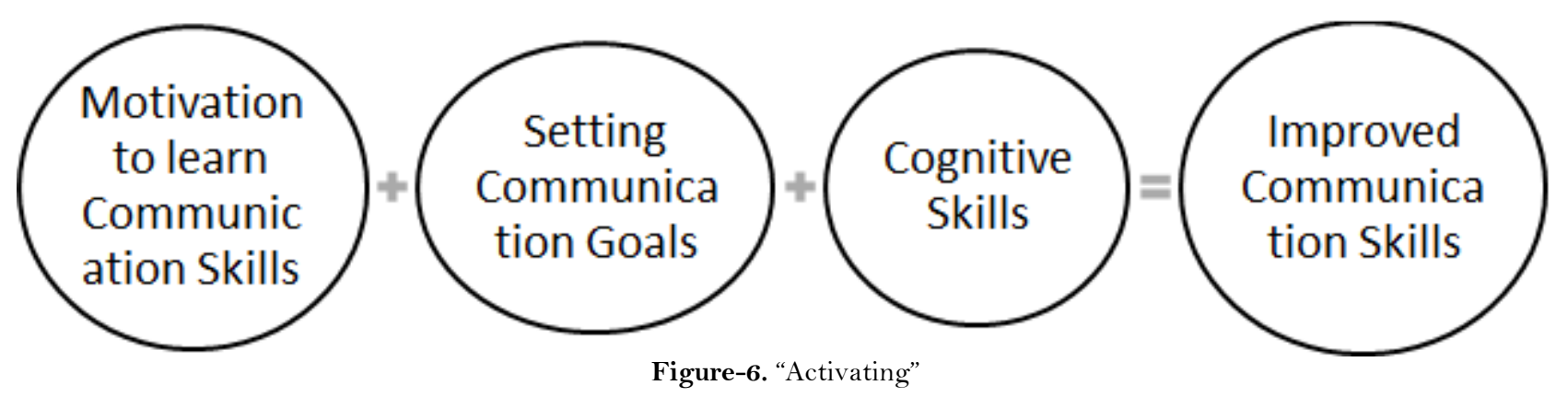

The activations for communications skills are designed considering these principles, for building motivation for communications skills some activations are (1) Inspirational speeches (2) Testimonies of great leaders about importance of communication skills and (3) Impact of communication skill on personal life. For setting communication goals key attitudes need to be acquired for impressive communication. These attitudes or communication goals are (1) Helpfulness (2) Patience (3) Avoiding conflict and (4) Confidence. These setting of communication goals is necessary as no matter how aware you are with the communication skills techniques and tips but if do not have the right feelings or attitude communication cannot be effective. The activation to build these feelings involves the use of NLP (Neuro Linguistic Programming) Anchoring. In these activations the state of mind will be linked to specific event or trigger. In these activations we will link communication goals with the event of communication so that anchor can fire to create a more positive communication. NLP anchoring is constructed on the idea of being able to get into the supreme powerful state for a specific task or event, and then being able to enter into that state exactly when you need it. After building motivation for communication skills and the attitude necessary for effective communication skills it is mandatory to developed cognitive skills. Activations for developing cognitive skills are (1) Role playing activities (2) Role imitations and (3) Rephrasing activity. For the improvement in product knowledge activations are (1) Role playing activity, this activity to be carried out b/w two agents where one agent would play a role of a customer and other to act as an agent. For this activity trainer have to predesign the scenarios of learning units where role playing activity need to be applied (2) Story telling activity, to be carried for learning units where agent need to remember a lot of information like product features ,product purpose ,product pricing ,product benefits ,policies etc.(3) Audio presentation of calls (4) Group base verbal presentations (5) Problem solving activities, trainer have to predesigned cases for problem solving activities.

\section{d) Organizing}

The last principle "Organizing" refers to the organized incorporation of these principals into the training program and in training curriculum for better implementation of these principles in training program. The organization principle recommends that complete training content shall be developed in which the principles of Inspiration, Exploration and Activation must be incorporated.

\section{Conclusion}

Call centers are the prime customer serving channel in today's business environment. The speedy growth of call centers and customer reliance on call centers puts very high focus and standards for the call center management in terms of customer satisfaction. Beside operational aspects of call center management training plays a significant role in achieving customer satisfaction through call centers. This paper, deals with the training in a call center and suggest a framework for training to improve customer satisfaction by improving product knowledge and communication skills of call center agents. The framework designed was based on four key principals' i-e Inspiring, Exploring, Activating and Organizing. The Inspiring principals suggest to build motivation in trainees about personal development through call center. The "Inspiring" principle recommends several strategies and themes to build motivation in trainees and how call center can play a significant role in improvising personal and professional development. The second principal "Exploring" increase ability to learn by enabling them to explore learning units by creating useful "Explorations". Several explorations were determined to improve learner's abilities. The third principal "Activating” rely heavily on activities base approach to learn. This principal create several activities related to call center learning. The fourth and the last principal "Organizing "recommends the organization and development of training content. The organization principle recommends that complete training content shall be developed in which the principles of Inspiration, Exploration and Activation must be incorporated. The framework was partially applied to newly hired agents, it is to be noted that only some parts of the framework was applied in isolation due to time constraint. This implementation reveals only slight improvement due to partial implementation and no significant difference observed between the samples on which the part of the framework was tested when compared with the sample on which framework was not applied. This slight difference was observed on "Product Knowledge" whereas the "Communication Skills" almost remains the same.

\subsection{Limitation and Recommendation}

- Complete framework is not applied to any of sample due to lack of time and resources. In order to get full advantage of the framework it is strongly suggested that the whole framework to be applied in the training programs.

- This training framework is designed explicitly for improvement in communication skills and product knowledge of call center agents in call centers, however this can also be used in other service industries.

- This framework is not a replacement of formal training content related to communication skills and product knowledge. This framework provide four philosophies and methods that need to be incorporated in training program to increase the effectiveness of training 


\section{References}

Bain, P., A. Watson, G. Mulvey, P. Taylor and G. Gall, 2002. Taylorism, trgets, and the pursuit of quantity and quality by call centre management. New TechnolWork Employ, 17(3): 170-185. View at Google Scholar $\mid$ View at Publisher

Dick, W., L. Carey and J.O. Carey, 2011. The systematic design of in- struction. 7th Edn., Boston, MA: Pearson.

Gustafson, K.L. and R.M. Branch, 2011. What is instructional design? In R.A. Reiser \& J.V. Dempsey (Eds.), Trends and issues in instructional design and technology. 3rd Edn., Boston, MA: Pearson. pp: 16-25.

Holman, D., R. Blatt and U. Holtgrewe, 2007. The global call center report: International perspectives on man- agement and employment. Sheffield, UK: Global Call Center Research Network.

Hsu, T.C., J. Lee-Hsieh, M.A. Turton and S.F. Cheng, 2014. Using the ADDIE model to develop online continuing education courses on caring for nurses in Taiwan. Journal of Continuing Education in Nursing, 45(3): 124-131. View at Google Scholar $\mid$ View at Publisher

Klein, J.D. and E.J. Fox, 2004. Performance improvement competencies for instructional technologists. TechTrends, 48(2): 22-25. View at Google Scholar | View at Publisher

Noe, R.A., 2010. Employee training and development. 5th Edn., New York: McGraw-Hill.

Tjosvold, D., N.Y. Chen, X. Huang and D. Xu, 2014. Developing cooperative teams to support individual performance and well-being in a call center in China. Group Decision and Negotiation, 23(2): 325-348. View at Publisher 